\title{
The evolution of the premaxillary protrusion system in some teleostean fish groups
}

\author{
William A. Gosline \\ Museum of Zoology, University of Michigan, Ann Arbor, \\ Michigan 48109, U.S.A.
}

(Accepted 12 February 1980)

(With 4 figures in the text)

\begin{abstract}
Changes in the acanthopteran (acanthopterygian) system of premaxillary protrusion are traced from its incipient representation in the iniomous (myctophiform) genus Aulopus to its fully evolved form in the percoids. Two complementary components of the system are differentiated. One is the protrusion of the premaxillary, brought about primarily by the anteroventral movement of a ligament attached to the rostral cartilage. The second, which distinguishes the acanthopteran system from other types of jaw protrusion, is the emplacement of a bony maxillary wedge between the skull and the protruded premaxillary.

The acanthopteran type of protrusion appears to have evolved in large-mouthed fishes, with the lateral expansion of the gape that occurs in such forms a fundamental element of this system's mechanics. The modifications that occur in small-mouthed fishes with little or no lateral expansion of the gape are discussed.

Premaxillary protrusion was investigated in available fish groups sometimes placed between the iniomous fishes and the percoids in classifications. Of these groups, the beloniform and cyprinodont fishes have developed protrusion systems of non-acanthopteran types.
\end{abstract}

\section{Contents}

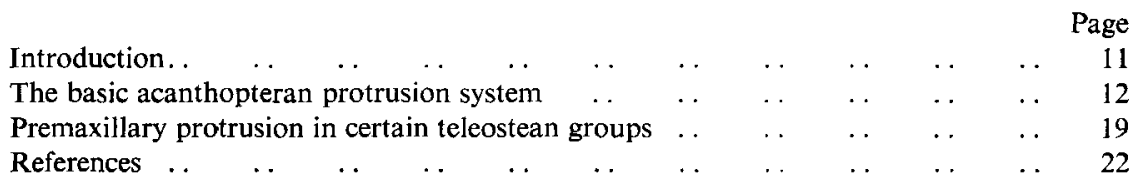

\section{Introduction}

The acanthopteran (or acanthopterygian) system of premaxillary protrusion (Alexander, $1967 a$ appears to form part of the inheritance of all higher teleosts. In a previous paper (Gosline, 1980) the development of this system was traced from the origin of its morphological components in lower teleosts to its incipient representation in the iniomous (myctophiform) genus Aulopus. The present paper deals with the evolution of the system from the Aulopus-condition to its fully-realized development in the higher teleosts.

Understanding of the complex acanthopteran protrusion system has evolved through the work of a number of authors but remains incomplete. Certain modifications in the present conceptual framework, most of it provided by Alexander (1967a), are suggested here. The first part of the paper deals with the main lines of evolutionary development in the system. The second part contains comments on the premaxillary protrusion in certain fish groups that have been placed between the iniomous and the percoid fishes in classifications. Jaw protrusion in various members of these groups has been treated in a number 
of excellent papers, but these for the most part deal with specialized representatives. Here, the concern is with the basal evolutionary changes that have preceded such specialized developments.

The approach throughout the paper is that of comparative morphology. Knowledge of what actually occurs in living fishes is, of course, fundamental to an understanding of premaxillary protrusion, but an attempt, such as this one, to trace evolutionary developments requires extrapolation, via morphological indications, to a range of material much of which cannot feasibly be studied alive.

\section{The basic acanthopteran protrusion system}

The acanthopteran protrusion system may be defined as that type of upper jaw movement in which a proximal part of the maxillary bone intervenes between the protruded premaxillary and the skull. This system can be divided into two complementary components. One of these is the protrusion of the premaxillary relative to the skull. The other is the emplacement of a maxillary wedge between the skull and the protruded premaxillary.

The evolutionary changes in the acanthopteran system can best be presented in linear fashion as a series of developments which together provide capabilities for greater premaxillary protrusion. There is, however, another and probably equally important aspect of these features that has recently been stressed by Liem (1979). The development of greater protrusibility in Perca, as compared to Aulopus, appears to have been accompanied by an increase in the ability to manipulate the system in a manner that provides the degree of protrusion suitable to the particular occasion. That this is true of Perca is suggested anatomically by the greater differentiation between the protrusion and the propping components of the acanthopteran system as compared to Aulopus. In Perca these two components are still integrated to the extent that both are apparently controlled by twisting of the maxillary, but in many higher teleosts the mechanism for protrusion and that for blocking the protruded premaxillary seem to be entirely separate.

Between Aulopus (Gosline, 1980) and Perca (van Dobben, 1935; Alexander, 1967a; see also, Greenwood, 1974: fig. 77) an increase in the amount of potential protrusion has been accompanied morphologically by the development of separate articular and ascending processes on the premaxillary (Fig. 1(d), (e)). Of the two, the articular process seems to

FIG. 1. (a), (b) Lateral and superior views respectively of structures associated with premaxillary protrusion in Perca flavescens. (c), Internal view of structures associated with the right half of the upper jaw in $P$. flavescens. (d), (e) Internal views of the right premaxillary of $P$. flavescens and Stizostedion vitreum respectively. (f), (g) External views of the right maxillary of Perca flavescens: (f) in resting position, i.e. with the premaxillary retracted, and (g) in twisted position, i.e. with the premaxillary protruded. (In (g) the inner limb has rotated forward relative to the outer limb, which is held in position by ligaments.) (h) Diagram of the premaxillary protrusion system in Perca.

ad, main part of the $M$. adductor mandibulae $\left(A_{2}+A_{3}\right)$; am, ligament between the inner limb of the maxillary and the ascending premaxillary process; ap, ascending premaxillary process; ar, articular premaxillary process; ca, rostral cartilage; $\mathrm{Cr}$, cranium; cs, cranial articular surface of the maxillary; ds, dental surface of the premaxillary; em, external proximal limb of the maxillary; ex, ethmoid-maxillary ligament; im, internal proximal limb of the maxillary; ma, maxillaris muscle $\left(A_{1}\right)$; Md, mandible; me, meniscus between the maxillary and the skull; mm, maxillary-mandibular ligament on which the maxillaris muscle inserts; $\mathrm{mr}$, ligament between the meniscus and the rostral cartilage; $\mathrm{Mx}$, maxillary; pm, membrane from the distal end of the premaxillary to the maxillary; Pp, palatine prong; Px, premaxillary; rc, ligament between the internal limb of the maxillary and the rostral cartilage; sa, articular surface of the premaxillary; su, articular surface on the articular process of the maxillary; and $t l$, transverse membrane across snout. 

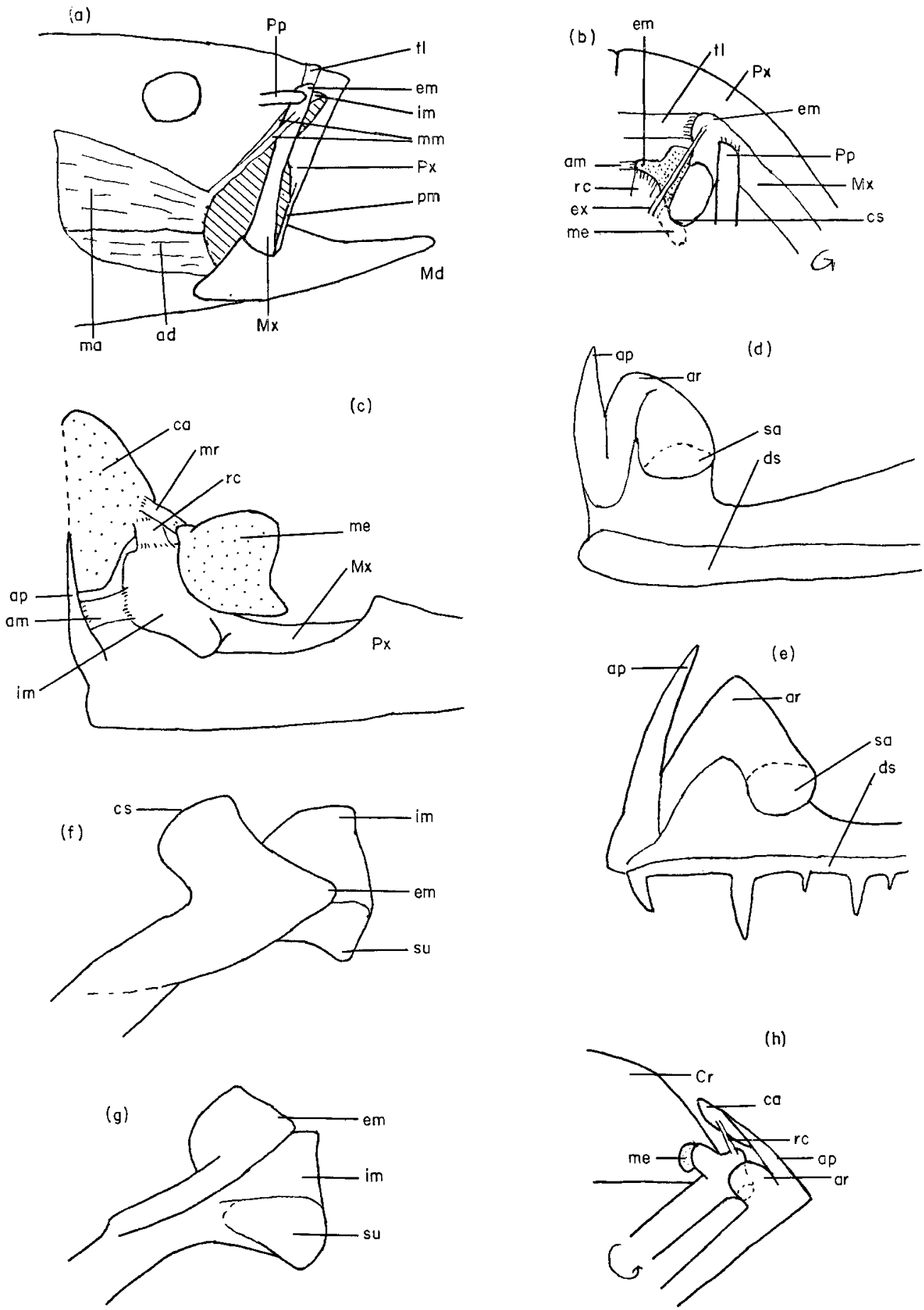

FIG. 1 
represent the lateral part of the single flange on the premaxillary of Aulopus and the ascending process to be a new development (which has, however, evolved repeatedly in teleosts).

In a large-mouthed fish with very little protrusion such as Aulopus, or even in one with no protrusion at all, when the mouth opens and the distal end of the premaxillary moves forward and outward, its proximal end rocks loose from the skull except at the very tip and any (maxillary) wedge between the premaxillary and the skull will strengthen the bite (Fig. 2(a), (b)). Such a maxillary prop extends between the skull and an articular area on the premaxillary in Aulopus and a host of other fishes with and without jaw protrusion. By contrast, the ascending process is associated with premaxillary protrusion and has nothing to do with the bite. By forcing a part of the premaxillary to remain anterodorsal to the skull at all times (Fig. 2(c), (d)), the ascending process controls the direction of premaxillary movement during protrusion. The greater the amount of protrusion, the longer the ascending process has to be to fulfill this function. In large-mouthed fishes such as Perca the forces exerted against the ascending and articular processes have different sources and press in somewhat different directions: the skull pushes the ascending process anterodorsally, and the maxillary wedges the articular process anterolaterally. The blades of the two processes in such fishes are often at an angle to one another as well as separate.

Both the extension and the propping components of the premaxillary protrusion system
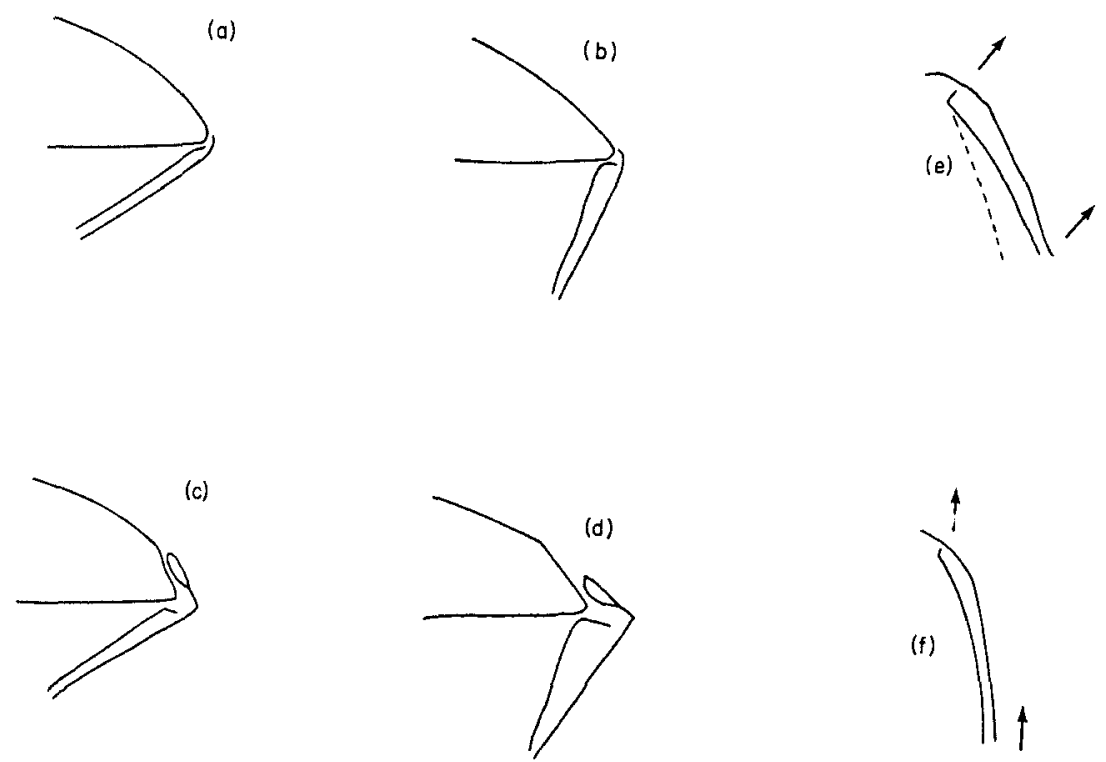

FIG. 2. Diagrammatic representations of upper jaw movements. (a), (b) When the upper jaw swings forward (b) the internal proximal limb of the maxillary may act as a supporting wedge between the premaxillary and the skull even though there is no premaxillary protrusion. (c), (d) When the upper jaw swings forward in a fish with moderate premaxillary protrusion (d), the anterior part of the ascending premaxillary process rocks upward as well as sliding over the skull. (e), (f) Superior views. When Perca (e) opens its mouth lateral expansion of the gape causes the distal end of the upper jaw to move laterally from its closed-mouth (dashed line) position, and the maxillary wedge must extend somewhat laterally to accommodate for this change. In small-mouthed forms (f) with no lateral expansion of the gape the maxillary wedge extends more directly forward. 
in Perca are rather complex. In protrusion, as the mouth opens the distal end of the premaxillary swings anteriorly as the proximal part of the same bone moves anteroventrally relative to the skull. The result is to lift the anterior part of the ascending process slightly upward and away from the skull as it slides forward (Fig. 2(c), (d)). A median rostral cartilage under the posterior parts of the ascending processes of the two premaxillaries mediates between the rigid skull and the sliding-rocking movements in the ascending processes.

The maxillary prop that holds the premaxillary in protruded position in Perca is not a simple vertical wedge inserted between the skull and the premaxillary with its verticallydirected bite. Rather, the maxillary wedge extends more or less anterolaterally (Fig. 2(e)) against a premaxillary that is prevented from moving outward by strong membranous attachments (tl and pm of Fig. 1(a)). As a result the maxillary wedge extends in a plane more or less at right angles to the bite in Perca (Fig. 1(d)); better indicated in the related, large-toothed Stizostedion, Fig. 1(e)). Presumably, this maxillary strut holds the premaxillary in protruded position sufficiently firmly to provide a grasping bite, but it seems probable that the premaxillaries are retracted when a stronger bite is needed. In fishes like Sphyraena, which habitually use a strong bite in feeding, premaxillary protrusion is greatly reduced or lost altogether.

In Perca, as in Aulopus, both protrusion and propping of the extended premaxillary seem to be primarily caused by the twisting of the maxillary shaft that occurs when the gape is expanded laterally (Alexander, 1967a; Gosline, 1980). This twisting causes the inner proximal limb of the maxillary to slide anterolaterally over its cranial articulation and forces the tip of this limb outward against the articular process of the premaxillary (Fig. 1(f), (g)). Usually this lateral pressure (Fig. 1(d)-(g)) against the premaxillary is considered to be the cause of its protrusion, e.g. by van Dobben (1935) and Alexander (1967a). To me it seems improbable that this outward pressure from the maxillary causes anteroventral movement in the premaxillary. A far more likely cause of protrusion, in my opinion, is a thin, flat ligament that extends anteroventrally from the ventral surface of the rostral cartilage to the inner proximal limb of the maxillary (rc in Fig. 1(c)) well above its articular tip. As the inner limb of the maxillary rolls forward over its cranial articulation (Fig. 1(f), (g)) it pulls this ligament anteroventrally, i.e. in the direction of protrusion, at the same time as the tip of the inner maxillary limb twists outward against the articular process of the premaxillary. [In Perca there are two other ligaments in the same area, one above and the other below the one discussed. The upper ( $\mathrm{mr}$ in Fig. 1(c)) extends from the meniscus between the maxillary and the skull to the rostral cartilage. As Alexander (1967a) pointed out, twisting of the maxillary shaft causes the meniscus to slide anterolaterally over the skull. The lower and stronger of the two ligaments (am in Fig. 1(c)), shown in Alexander's illustrations (1967a: fig. 1; 1967b: fig. 10), extends from the inner limb of the maxillary transversely to the ascending process of the premaxillary at the base of the rostral cartilage. This ligament appears to be primarily concerned with holding the premaxillary in position relative to the inner limb of the maxillary.] As envisioned here, the ligament between the rostral cartilage and the inner limb of the maxillary is the primary cause of protrusion in Perca, with the maxillary wedge between the premaxillary and the skull merely moving into blocking position during protrusion (Fig. 1(f), (g)).

From the generalized acanthopteran protrusion system represented in an incipient state in Aulopus and in a fully developed form in Perca, various lines of modification have 
repeatedly evolved. The two extremes in this regard are the secondary loss of protrusion on the one hand and its exaggerated development on the other. These extreme types are briefly considered after a discussion of the modifications that have evolved repeatedly in the protrusion system of small-mouthed acanthopterans.

In Aulopus, Perca, and other large-mouthed forms the primary means of both effecting and maintaining premaxillary protrusion seems to be a twisting of the maxillary shaft brought about by lateral expansion of the gape. However, in small-mouthed fishes the gape does not widen much, and other means of effecting and maintaining protrusion are adopted. In the following paragraphs the two complementary components of the system are discussed separately.

So far as the method of holding the premaxillary in protruded position is concerned (see also, the discussion of this matter in Liem, 1979) there is in small-mouthed forms as compared to Perca a shift both in the position of the maxillary wedge behind the premaxillary and in the immediate agency that holds the wedge in position. In both small- and large-mouthed forms the maxillary is moved into blocking position behind the premaxillary by twisting of the maxillary shaft. In small-mouthed forms, however, it appears to be held in place not by the continued lateral expansion of the gape (Alexander, 1967a) but by contraction of the maxillaris component of the $\mathrm{M}$. adductor mandibulae.

In most fishes with a basal acanthopteran type of premaxillary protrusion, including Aulopus and Perca, the maxillaris component of the M. adductor mandibulae $\left(A_{1}\right.$ of authors, see Winterbottom, 1974) inserts on the back of a ligament that extends between the posterior part of the mandible below and an anterior part of the maxillary shaft above (Fig. 1(a)). The maxillaris muscle undergoes many modifications which seem to take on various functions, but in its basic configuration described above its contraction appears to be associated with the blocking of the protruded premaxillary rather than with the protrusion component of the acanthopteran system. Protrusion occurs as the mandible is being lowered, but as Rognes (1973) has demonstrated for Norwegian labrids contraction of a maxillaris muscle of the Perca-type will in part raise the mandible and in part pull back on the proximal portion of the maxillary shaft. Osse's (1969: fig. 20) electromyographic data indicate the same function in Perca in that the maxillaris muscle begins to contract just ahead of the contraction in the main part of the $\mathrm{M}$. adductor mandibulae. In Aulopus, Perca, etc., contraction of the maxillaris component appears to supplement the lateral expansion of the mouth cavity in maintaining the maxillary block against premaxillary retraction, but in small-mouthed forms it apparently has taken over the entire role. [The exact method by which the blocking action of the maxillaris muscle operates remains unclear. Presumably in pulling back on the proximal part of the maxillary shaft contraction of the maxillaris muscle affects the cranial-maxillary articulation in such a way as to temporarily prevent the maxillary from rotating back over this articulation to its retracted-premaxillary position (see Rognes, 1973: 125).]

In small-mouthed fishes, as compared to Perca, there is also a forward shift in the articulation between the maxillary wedge and the premaxillary (Figs 2(f); 3(a), (b), (e)). As the mouth opens in Perca, widening of the gape causes the distal end of the premaxillary to move laterally at the same time as it swings downward and forward, and the maxillary wedge moves anteriolaterally to fill the space that opens up behind (Figs 1(e), (f), 2(e)). In small-mouthed fishes with little or no widening of the gape, the premaxillary and the maxillary wedge both lose the lateral components of their movements. The axis of the 
maxillary wedge becomes nearly longitudinal, blocking the premaxillary from the rear rather than from a posterolateral direction (Fig. 2(f)). This change in direction of the blocking force against the protruded premaxillary is accompanied by changes in premaxillary structure and in the arrangements for holding it in position. As to structure, the articular area on the premaxillary of small-mouthed fishes with jaw protrusion shifts forward (Fig. 3(b), (e)) relative to its position in large-mouthed forms (Figs 1(d), (e), 3(d)), and the articular process merges into the side of the ascending process. As to arrangements for holding the premaxillary in position against forward pressure from the maxillary wedge, the membrane between the distal end of the premaxillary and the maxillary holds that end of the premaxillary in place as before. Anteriorly, however, there is a strengthening of the membrane that extends across the front of the snout and encloses the ascending premaxillary processes. Usually there is also an elongation of the external proximal limb of the maxillary that extends into the lateral part of this membrane (Fig. 3(a), as compared to 3(c)). Because of this extension, the external and internal proximal limbs of the maxillary sometimes form two tines of a fork which, when the fork is twisted, grip the combined ascending-articular process firmly between them (Anker, 1974).

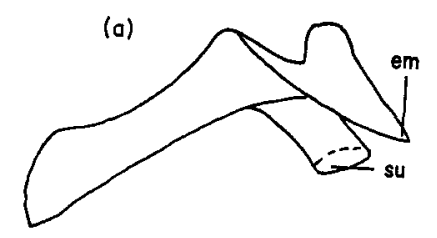

(a)
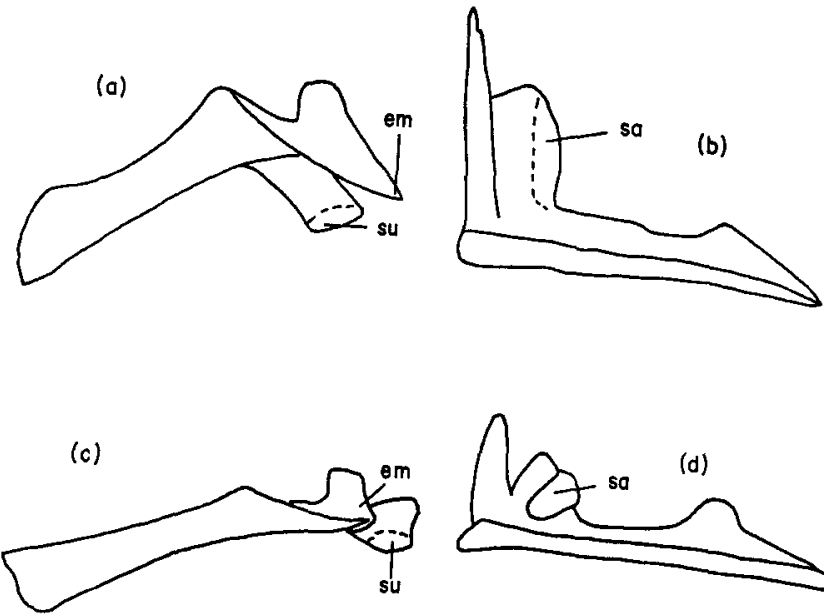

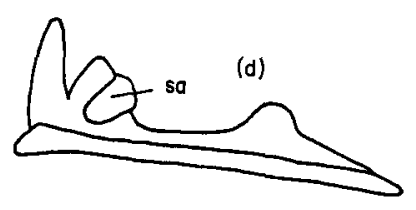

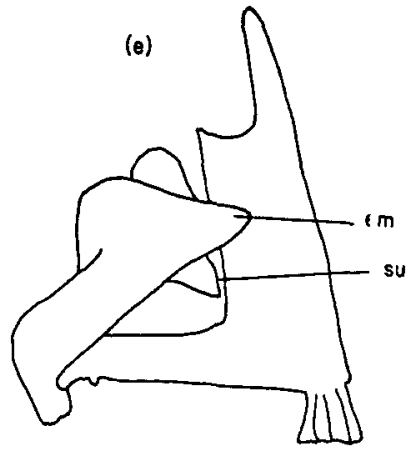

FIG. 3. (a), (c) external view of the right maxillary of Lepomis gibbosus (a) compared with that of the related, large mouthed Micropterus salmoides (c). (b), (d) Internal view of the right premaxillaries of (b) Lepomis gibbosus and (d) Micropterus salmoides. (e) external view of the right premaxillary and maxillary of Lagodon rhomboides. (The teeth between the anterior incisiform series and the posteriormost molar are not shown.) Labels as in Fig. 1.

As to the mechanism involved in the protrusion component of the acanthopteran system, this shifts from widening of the gape in Perca to lowering of the mandible in smallmouthed forms. A moderate stage of this development occurs in the small-mouthed centrarchid Lepomis gibbosus. Here, lowering of the mandible seems to be the principal cause of protrusion, which it brings about by maxillary twisting as in Perca. (Lepomis gibbosus has the same ligament extending forward from the rostral cartilage to the inner limb of the maxillary that was described for Perca). Even in large-mouthed fishes, lowering of the mandible causes some protrusion (Alexander, 1967a), and it is presumably this 
component of the protrusion that has been emphasized by Lepomis gibbosus. Another point regarding L. gibbosus is that, as in Perca, some forward swinging of the distal end of the premaxillary seems to take place when the mouth opens.

A more advanced stage of specialization in small-mouthed forms is represented by the sparid Lagodon rhomboides (Fig. 3(e)) and by the Norwegian labrids investigated by Rognes (1973). Here, twisting of the maxillary seems to have been lost as an agency bringing about protrusion, though it is retained as a method of blocking the extended maxillary. Instead, the cause of protrusion is a direct downward pull of the descending mandible on the distal end of the maxillary, which in turn forces the premaxillary anteroventrally ahead of it. Long, strong ascending premaxillary processes prevent the distal end of the premaxillary from rocking forward relative to its proximal end, so the result of the maxillary force is to cause premaxillary protrusion.

Another development associated with the adoption of mandibular lowering as a protrusion agency has to do with occlusion (see also Anker, 1974). In fishes like Aulopus, with premaxillary protrusion primarily dependent on spreading of the mandibular rami which necessitates a flexible attachment between the upper and lower jaws, there seems to be no assurance regarding the particular stage of premaxillary protrusion the mandible may bite against. The small teeth of Aulopus are in broad bands in both jaws, so the matter of a precise occlusion seems unimportant. An exact occlusion, such as that necessary to nipping fishes (Fig. 3(e)), appears to be restricted to forms in which there is a strict coordination between protrusion and mandibular lowering, i.e. between the movements of the upper and the lower jaws. This coordination is usually attained in fishes, at least in part, by a tightening of the membranous attachment between the distal end of the maxillary and the mandible.

There is, however, another aspect of occlusion in fishes with protrusile premaxillaries. In forms like Aulopus, Perca and Lepomis gibbosus the protrusion and blocking components of the acanthopteran system are both effected by maxillary twisting and are hence of necessity more or less closely synchronized. In fishes in which mandibular lowering is the cause of protrusion the necessity for synchronization in the two components is no longer present. Blocking of the premaxillary at any stage of protrusion can be effected through the independent system of maxillaris muscle contraction. Rognes (1973) has shown that in Norwegian labrids this blocking system is brought into play at a particular stage of protrusion, presumably that which provides the most advantageous occlusion, and it seems probable that other higher teleosts, e.g. Lagodon (Fig. 3(e)), use similar systems.

In fishes with long ascending premaxillary processes and an exact occlusion, e.g. most triacanthoids (Tyler, 1968), the mandible is apparently raised against a premaxillary at a fixed stage in protrusion. From this type of development it seems to be a short evolutionary step via reduction or loss of the ascending premaxillary process to forms like the tetraodontoids in which the upper jaw rocks forward around a palatine fulcrum as the mandible is raised.

The two extreme types of development in the acanthopteran protrusion system may be briefly noted. One of these is the secondary reduction or complete loss of premaxillary protrusion that has evolved repeatedly. There appear to be two quite different causes for such a loss. In one, associated with the simple reduction in the amount of premaxillary movement that occurs in such fishes as Percopsis, Amblyopsis, Sphyraena, and Percina, separate articular and ascending processes on the premaxillary are often retained. The 
other type of protrusion loss occurs in fishes in which the forward rocking of the distal end of the premaxillary around a proximal fulcrum is emphasized. This may lead to a more or less complete loss of both ascending and articular premaxillary processes in such fishes as the syngnathoids (Fig. 4(a)), Echeneis, or, along another line of development, scarids and tetraodontids.
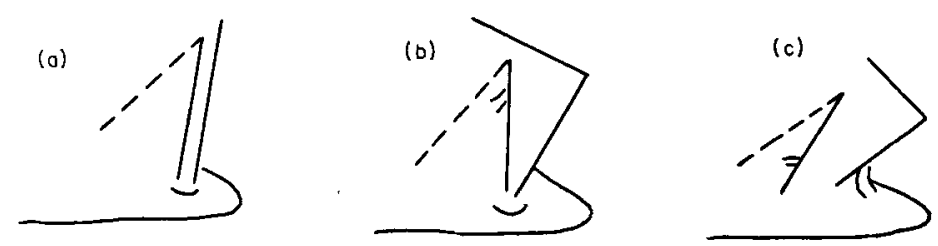

FIG. 4. Diagrammatic representations of certain extreme types of upper jaw movement. (a) The complete absence of premaxillary protrusion in Syngnathus. (b), (c) Two types of extensive protrusion. In (b), the distal ends of the maxillary and premaxillary move forward together during protrusion. In (c) the distal end of the premaxillary moves forward more or less independently; movement in the distal end of the maxillary is relatively slight, and the attachment of the maxillaris muscie, indicated by the paired lines, shifts distally along the maxillary shaft.

The opposite extreme, that of very extensive premaxillary protrusion, is usually accompanied in the acanthopteran system by elongation of the ascending premaxillary processes and a shift, discussed above, to mandibular lowering as a protrusion mechanism. It seems possible to trace stages in the development of extensive protrusion via the upper jaw structures of the zeiform genus Zenopsis, which retains the usual rostral cartilage but appears to have lost the membrane between this cartilage and the internal limb of the maxillary, to either the nandids (Liem, 1970) which have lost the rostral cartilage, or to Atherina presbyter (Alexander, 1967b) in which the long ascending processes slide over the major unit of the rostral cartilage. Throughout the development of this type of protrusion the distal end of the maxillary swings forward with the premaxillary in the usual fashion and forms a "brace" (Liem, 1970) for the protruded premaxillary (Fig. 4(b)).

A different type of premaxillary extension has evolved repeatedly among small-mouthed fishes, some with and some without a basically acanthopteran type of protrusion, e.g. Cyprinus, Parexocoetus, Fundulus, Menidia, Eucinostomus and Pterophyllum. In this type of protrusion, a lip-like membrane extends forward from the distal part of the premaxillary to the outside of the mandible (Fig. 4(c)). When the mandible is lowered it pulls the premaxillary forward more or less independently of the maxillary. The amount of movement in the distal end of the maxillary in such fishes tends to become reduced, the attachment of the maxillaris muscle shifts downward along the maxillary shaft, and in the extreme development of this type of protrusion among cyprinodontids, the maxillary becomes incorporated into the cheek.

\section{Premaxillary protrusion in certain teleostean groups}

Upper jaw structure was investigated in available groups that have sometimes been placed between the iniomous and the percoid fishes in classifications, i.e. roughly those included in the Mesichthyes of such authors as Gregory (1933). The objective was to determine in so far as possible the stage in the series of developments from Aulopus to Perca from which their upper jaw structures evolved. 
The premaxillary seems to provide the best individual indicator of this transition. The single raised flange at the proximal end of the premaxillary with the lateral rim of this flange forming an articular surface for the maxillary characteristic of the iniomous fishes (Paxton, 1972; Sulak, 1977) seems to be a basic structural feature found in a number of lower teleostean fishes including Clupea (Kirchhoff, 1958). This type of premaxillary occurs in the extinct ctenothrissiform fishes (Patterson, 1964; Gaudant, 1978) and in modern beloniform and cyprinodont groups. A more or less separate ascending premaxillary process in addition to the articular process appears to have been present in the Cretaceous percopsiform genus Sphenocephalus (Rosen \& Patterson, 1969) and occurs in a more or less well-developed state in at least some member of all of the groups considered here except the beloniform, cyprinodontiform, and gasterosteiform fishes. However, as noted in the previous section ascending and articular premaxillary processes have repeatedly merged in higher teleosts, and it is often impossible to say whether the single remaining process is a primary or secondary development. In such forms it is necessary to use other jaw structures as criteria of evolutionary status.

So far as premaxillary movement is concerned, all of the mesichthyine groups investigated either include members with a more advanced type of protrusion than the iniomous fishes or they show indications that such a protrusion has secondarily been lost. However, if, as here, the acanthopteran system is defined as one in which the maxillary provides a bony wedge against a proximal part of the protruded premaxillary, two of the groups considered developed a protrusion that is of non-acanthopteran type, namely the beloniform and cyprinodont fishes. Both groups contain modern forms with upper jaws that range between the extremes of no independent premaxillary movement [the belonids and most hemiramphids (Alexander, 1967b) among beloniform fishes and the adrianichthyids (Weber \& de Beaufort, 1922) among cyprinodontiform fishes) and well-developed protrusion (Parexocoetus (Parin, 1961) and most cyprinodonts (Alexander, 1967b)]. Both of these extreme types are assumed here to have evolved from some intermediate upper-jaw condition such as that now best represented in Arrhamphus among beloniform fishes and Aplocheilus (Alexander, 1967b) among cyprinodonts. These two genera have upper jaw structures resembling those of the iniomous genus Aulopus in a number of respects: there is a palatine prong extending over a proximal part of the maxillary shaft (Gosline, 1980); the proximal part of the premaxillary has a single flange the lateral rim of which articulates with the underlying maxillary; and the internal proximal limb of the maxillary extends beyond the premaxillary articulation to below (ahead of) the rostral cartilage to which it is membranously attached.

The upper jaws of Arrhamphus and Aplocheilus resemble each other but not that of Aulopus in the expansion of the premaxillary flanges to form a flattened cap over the rostral cartilage. This development may be related to the fact that Aplocheilus and presumably Arrhamphus feed at the surface of the water whereas Aulopus is a benthic fish. There are also differences in the structures associated with the upper jaw movements of Arrhamphus and Aplocheilus. In Arrhamphus, as in Aulopus, widening of the gape seems to cause a slight forward movement of the premaxillary, but the maxillaris muscle (pace Rosen, 1964: pl. 14), as in other beloniform fishes examined, has been lost. In Aplocheilus the relatively greater premaxillary protrusion may apparently be brought about either by lowering of the mandible or by contraction of the maxillaris muscle (Alexander, 1967b), but widening of the gape has no effect on protrusion. Whatever the genetic relationship, or 
lack of it, between the type of jaw protrusion developed in Parexocoetus and cyprinodonts, the evidence from modern beloniform and cyprinodontiform fishes suggests that they never developed a protrusion of acanthopteran type beyond an incipient Aulopus-like stage.

As noted above, the gasterosteiform fishes are the only other group investigated without a definite indication of separate ascending and articular premaxillary processes. In this group (sensu lato of Pietsch, 1978) three quite different types of mouth structure are represented (four if Indostomus is included, Banister, 1970: fig. 11), all of them specialized. In the gasterosteids (Kampf, 1961; Alexander, 1967a; Anker, 1974) there is a long ascending premaxillary process, no separate articular process, and a well-developed maxillary blocking system for the protruded premaxillary. The upper jaw structures of gasterosteids bear a strong resemblance to those illustrated for the Eocene Asineops by Rosen \& Patterson (1969: fig. 37). The upper jaw structures of both Asineops and gasterosteids, though they may have developed independently, seem to be of an advanced acanthopteran type (Alexander, 1967a) that has evolved repeatedly in percoid fishes. Pegasids (Pietsch, 1978) have a far more specialized jaw protrusion than the gasterosteids, and one in which the premaxillary has neither an ascending nor an articular process. However, the bone labeled "?" in Pietsch's illustration of the extinct, related Ramphosus (1978: fig. 14) suggests to me an ascending premaxillary process. The direction of evolution traced by Okamura (1970) in the unrelated macrourid fishes may be analogous to that which has led to the protrusion system of Pegasus and of other higher teleosts with small, downwardly projectable mouths

In the zeiform fishes (Hofer, 1938) the articular and ascending premaxillary processes are not separate but give every indication of having become united secondarily. In Zenopsis (examined) the articular process is a well-demarcated wing extending laterally from the long ascending process. In numerous respects (see above) the zeid upper jaw seems to represent a stage in upper jaw specialization about midway between that of the two percoid genera Perca and Nandus (Liem, 1970).

Among the remaining groups examined, all containing at least some member with separate articular and ascending premaxillary processes, the gadiform, percopsiform, and amblyopsoid fishes (Rosen, 1962) are characterized by peculiarities in the maxillaris muscle. From these three groups the beryciform fishes, basal percoids, and Channa among the anabantoids (sensu lato) differ not only in the more normal maxillaris configuration but in an apparently advanced feature of the protrusion mechanism.

In the gadiform, percopsiform, and amblyopsoid fishes investigated, as in Aulopus and for that matter in cyprinodonts, the internal proximal limb of the maxillary extends medially below (ahead of) the rostral cartilage (forming the internal hook of authors). In the berycoids, Channa, and the basal percoids examined the inner limb of the maxillary extends down alongside the rostral cartilage with a strong membrane extending longitudinally between the two units (see the first section of this paper). In the members of the one remaining group to be discussed, the percesocine fishes, I can find no membrane extending forward from the rostral cartilage to the internal proximal limb of the maxillary. In this respect the percesocines seem to resemble the Aulopus-gadiform type of upper jaw structure rather than that of the berycoid-percoid groups. How much significance should be attributed to this feature of upper jaw structure is far from clear.

The percesocine fishes (sensu Gosline, 1962), like the gasterosteiform fishes, include 
features with quite different upper jaw structures. The only distinct, separate articular and ascending premaxillary processes that $I$ have seen in the group are in the younger stages (to $175 \mathrm{~mm}$ in standard length) of Sphyraena barracuda. Even in this fish, which has no premaxillary protrusion, the two processes grow together though they apparently do not completely fuse in larger individuals.

As compared with sphyraenids, the other percesocines are small-mouthed groups, but their mouths open in different directions. In polynemids the mouth is more or less subterminal but when opened faces forward. The distal ends of the maxillary and premaxillary swing downward and forward as the mouth opens but there is little or no protrusion in the proximal end of the premaxillary. In the bottom-feeding mugilids the mouth is approximately terminal but opens downward, with protrusion in the proximal end of the premaxillary but relatively little forward movement in the distal end of the maxillary. The reduction in maxillary swinging is accompanied by a shift in the maxillaris attachment toward the distal end of the maxillary shaft (Eaton, 1935), as in other forms with reduced maxillary movement. So far as the direction of the mouth opening is concerned, the atherinids, with terminal mouths that open forward, are intermediate between the polynemids and mugilids.

Atherinids show great variation in protrusion capabilities, ranging from forms like Melanotaenia with little or none to fishes with extensive protrusion of two different types. During such protrusion as may occur, a proximal limb of the maxillary presses against a lateral part of a process on the premaxillary in typical acanthopteran fashion.

One of the two extensive types of protrusion occurs in Atherina presbyter investigated by Alexander (1967b). In this fish there are long ascending processes and the distal end of the maxillary swings anteriorly during protrusion to provide a forwardly-rocking brace for the premaxillary (Fig. 4(b)) about as in Nandus (Liem, 1970). This type of protrusion seems structurally derivable via such forms as Atherina boyeri from a basal type of mouth structure such as that represented in Atherinomorus (Pranesus) endrachtensis. In Atherinomorus the shorter ascending processes move with the rostral cartilage rather than sliding over it as in Atherina presbyter, and the main cause of protrusion seems to be the twisting of the maxillary shaft rather than the direct downward pull of the mandible.

In the other type of protrusion, that which occurs in such genera as Craterocephalus, Chirostoma, Menidia, Atherinops, and, I think, in the phallostethid genus Phenacostethus, a lip-like membrane between the premaxillary and the mandible carries the premaxillary forward when the mandible is lowered. In the more specialized forms with this type of protrusion there is little maxillary movement, and the maxillaris attachment is displaced toward the distal end of the maxillary (Fig. 4(c)).

I would like to thank Drs Karel F. Liem and George V. Lauder, Jr. for their helpful comments on the manuscript.

\section{REFERENCES}

Alexander, R. McN. (1967a). The functions and mechanisms of the protrusible upper jaws of some acanthopterygian fish. J. Zool., Lond. 151: 43-64.

Alexander, R. McN. (1967b). Mechanisms of the jaws of some atheriniform fish. J. Zool., Lond. 151: $233-255$.

Anker, G. C. (1974). Morphology and kinetics of the head of the stickleback, Gasterosteus aculeatus. Trans. zool. Soc. Lond. 32: $311-416$. 
Banister, K. E. (1970). The anatomy and taxonomy of Indostomus paradoxus Prashad \& Mukerji. Bull. Br. Mus. nat. Hist. (Zool.) 19: 179-209.

Eaton, T. H. (1935). Evolution of the upper jaw mechanism in teleost fishes. J. Morph. 58: 157-172.

Gaudant, M. (1978). Recherches sur l'anatomie et la systématique des cténothrissiformes et des pattersonichthyiformes (poissons téléosteens) du Cénomien du Liban. Mem. Mus. natn. Hist. nat., Paris, n. s., (C) 41: 1-124.

Gosline. W. A. (1962). Systematic position and relationships of the percesocine fishes. Pacif. Sci. 16: $207-217$.

Gosline, W. A. (1980). The evolution of some structural systems with reference to the interrelationships of modern lower teleostean fish groups. Jap. J. Ichthyol. 27: 1-28.

Greenwood, P. H. (1974). The cichlid fishes of Lake Victoria, East Africa: the biology and evolution of a species flock. Bull. Br. Mus. nat. Hist. (Zool.) Suppl, 6: 1-134.

Gregory, W. K. (1933). Fish skulls: a study of the evolution of natural mechanisms. Trans. Am. phil. Soc. (N. S.) 23: $75-481$.

Hofer, H. (1938). Bau und Mechanik des Schädels von Zeus pungio. Zool. Jb. (Anat.) 64: 483-510.

Kampf, W. D. (1961). Vergleichende funktionsmorphologische Untersuchungen an den Viscerocranien einiger räuberisch lebender Knochenfische. Zool. Beitr. (N. S.) 7: 321-445.

Kirchhoff, H. (1958). Functionell-anatomische Untersuchungen des Visceralapparates von Clupea harengus L. Zool. Jb. (Anat.) 76: 461-550.

Liem, K. F. (1970). Comparative functional anatomy of the Nandidae (Pisces: Teleostei). Fieldiana, Zool. 56: $1-166$.

Liem, K. F. (1979). Modulatory multiplicity in the feeding mechanism in cichlid fishes, as exemplified by the invertebrate pickers of Lake Tanganyika. J. Zool., Lond. 189: 93-125.

Okamura, O. (1970). Studies on the macruroid fishes of Japan: morphology, ecology and phylogeny. Rep. Usa mar. biol. Stn Kochi Univ. 17: 1-179.

Osse, J. W. M. (1969). Functional morphology of the head of the perch (Perca fluviatilis L.): an electromyographic study. Neth. J. Zool. 19: 289-392.

Parin, N. V. (1961). The bases for the classification of the flying-fishes (Families Oxyporhamphidae and Exocoetidae). Trudy Inst. Okeanol. 43: 92-183. (In Russian; cited from the U.S. Nat. Mar. Fish. Serv. translation.)

Patterson, C. (1964). A review of the Mesozoic acanthopterygian fishes, with special reference to those of the English Chalk. Phil. Trans. R. Soc. (B) 247: 213-482.

Paxton, J. R. (1972). Osteology and relationships of the lanternfishes (Family Myctophidae). Bull. Los Ang. Cty Mus. Sci. No. 13: 1-81.

Pietsch, T. W. (1978). Evolutionary relationships of the sea moths (Teleostei: Pegasidae) with a classification of gasterosteiform families. Copeia 1978: 517-529.

Rognes, K. (1973). Head skeleton and jaw mechanism in Labrinae (Teleostei: Labridae) from Norwegian waters. Arbok Univ. Bergen, (Math. nat.) 1971 (4): 1-149.

Rosen, D. E. (1962). Comments on the relationships of the North American cave fishes of the Family Amblyopsidae. Am. Mus. Novit. No. 2109: 1-35.

Rosen, D. E. (1964). The relationships and taxonomic position of the halfbeaks, killifishes, silversides, and their relatives. Bull. Am. Mus. nat. Hist. 127: 217-268.

Rosen, D. E. \& Patterson, C. (1969). The structure and relationships of the paracanthopterygian fishes. Bull. Am. Mus. nat. Hist. $141: 357-474$.

Sulak, K. J. (1977). The systematics and biology of Bathypterois (Pisces, Chlorophthalmidae) with a revised classification of benthic myctophiform fishes. Galathea Rep. 14: 49-108.

Tyler, J. C. (1968). A monograph on plectognath fishes of the Superfamily Triacanthoidea. Monogr. Acad. natn. Sci. Philad. 16: 1-364.

Van Dobben, W. H. (1935). Uber den Kiefermechanismus der Knochenfische. Archs néerl. Zool. $2:$ 1-72.

Weber, M. \& deBeaufort, L. F. (1922). The fishes of the Indo-Australian Archipelago. 4: Leiden: E. J. Brill.

Winterbottom, R. (1974). A descriptive synonymy of striated muscles of the Teleostei. Proc. Acad. natn. Sci. Philad. 125: 225-317. 
